\title{
Effect of Coarse Content on Compaction Test
}

\author{
Badee Alshameri (iD \\ National University of Sciences and Technology (NUST), Pakistan
}

\section{Keywords}

Compaction,

Coarse material

Maximum dry density,

Optimum moisture content,

Specific gravity

\begin{abstract}
The compaction is a mechanism to densify the loose soils. The maximum soil densification can be achieved by optimization of the desirable optimum moisture content (OMC) and maximum dry density (MDD). The maximum dry density and the optimum moisture content were affected by several parameters. The coarse content (CC) is one of these parameters. This paper studied the effect of the coarse content on the compaction parameters (MDD, OMC). Several sand-kaolin mixtures had coarse content ranged from $30 \%$ to $80 \%$ and moisture content ranged from $12 \%$ to $20 \%$ were used to inspect the relationship between CC, specific gravity (Gs), MDD, OMC, and bulk density. The results presented five empirical correlations with coefficient of determination $\left(\mathrm{R}^{2} \geq 0.98\right)$ between CC, Gs, MDD, OMC and bulk density. The comparison between the current study and previous researchers indicated that both soil type and moisture content have significant effect on the efficiency of the empirical correlation equations between the maximum dry density, specific gravity, and coarse content. The results indicated a linear relationship between coarse content toward maximum dry density and specific gravity where both MDD and Gs increased with an increase CC. In contrary, the results showed non-linear relationship between optimum moisture content and coarse content where OMC decrease with an increase CC.
\end{abstract}

\begin{abstract}
1.Introduction
The compaction is a mechanism used to rearrange the positions of particles to achieve higher density. The compaction depends on several parameters [1] which can be classified into two main categories: (1) Procedure parameters and (2) Compacted material properties. In the procedure, the parameters were; the hammer weight, number of blows, high and inclination of drops, mould size and type of compaction [1]. The compacted material properties parameters can be included the particle size, the materials conditions and the moisture content [2-8]. Table 1 tabulated the effect of parameters on the maximum dry density (MDD) and optimum moisture content (OMC) from previous researchers.
\end{abstract}

According to Wang et al. [5,6], the coarse content showed curve relationship with the maximum dry density. The result on Wang et al. [6] showed that the MDD increased with the increment of the coarse content from 10 to $20 \%$ then MDD decreased with further increment of the coarse content from 40 to $80 \%$. Similar behaviour observed on Wang et al. [5] where MDD increase with an increase CC from 10 to $50 \%$ then decrease with further increment of CC from 60 to $80 \%$. In addition, Wang et al. [6] and Omotosho [9], indicated that the increment of the coarse content caused decrement of OMC. Wang et al. [5] stated that there is non-linear relationship between the increment of the coarse content and OMC. With the increment of the coarse content from 10 to $40 \%$ resulted decreased the OMC then with further increment on CC from $40 \%$ to $80 \%$, the OMC increased.

The previous researchers studied the effect of the coarse content on compaction parameter using gravel size $[5,9,10]$. Other researchers correlated between CC and compaction parameters using different fine materials such as bentonite [11], Fly ash with soil mixture [12-14]. While other researchers did not include the fine material on the their studies [6]. This study, focus on the effect of wide range of coarse content (coarse content ranged from $20 \%$ to $80 \%$ ) on the maximum dry density MDD and optimum moisture content OMC by using sandkaolin mixtures in standard compaction effort as well as present a new empirical correlation between coarse content, maximum dry density, optimum moisture content, bulk density, and specific gravity.

\section{Materials and test procedures}

Six sand-kaolin mixtures were used and tested under different moisture content. Those mixtures were as the followings: $80-20,70-$ $30,60-40,50-50,40-60,30-70$ (where the first number represented the coarse content and the second one represented the fine content). In these mixtures, the sand with particle size less than $3.35 \mathrm{~mm}$ was used as coarse materials and the fine material was a kaolin. The kaolin had minimum $40 \%$ particle size $<2 \mu \mathrm{m}$, and maximum $0.05 \% 325$ of $45 \mu \mathrm{m}$ mesh residues. Figure 1 showed the grain size distribution for coarse materials.

The preparation of samples and the procedure of laboratory tests were one according to standard compaction effort in ASTM D698 [1] using 6" mould and procedure of method B. The dry density was calculated according to equations 1 and 2 :

Table 1. Effect of coarse and fine content toward MDD and OMC

\begin{tabular}{|c|c|c|c|c|}
\hline Content & Effect of CC toward MDD & & Material & Refe. \\
\hline $\mathrm{CC}$ & $\begin{array}{l}\text { Increased MDD to the highest } \\
\text { value at CC }=20 \% \text { then } \\
\text { decreased beyond this value }\end{array}$ & Decreases & Crushed mudstone & [6] \\
\hline CC & $\begin{array}{l}\text { Increased } \mathrm{MDD} \text { to the highest } \\
\text { value at } \mathrm{CC}=60 \% \text { then } \\
\text { decreased beyond this value }\end{array}$ & Decreases & Crushed sandstone & [5] \\
\hline CC & $\begin{array}{l}\text { Increased MDD to the highest } \\
\text { value at } C C=8 \% \text { then } \\
\text { decreased beyond this value }\end{array}$ & Decrease & lateritic soil & [9] \\
\hline FC & $\begin{array}{l}\text { Increased } \mathrm{MDD} \text { to the highest } \\
\text { value at } \mathrm{FC}=15 \% \text { then } \\
\text { decreased beyond this value }\end{array}$ & Increase & $\begin{array}{l}\text { Bentonite sand } \\
\text { mixture }\end{array}$ & [11] \\
\hline FC & Decrease & Increase & $\begin{array}{l}\text { Fly ash-soil } \\
\text { mixtures }\end{array}$ & {$\left[\begin{array}{l}{[12,13} \\
{[}\end{array}\right.$} \\
\hline FC & Decrease & Increase & $\begin{array}{l}\text { Mixture of gravel, } \\
\text { sand, silt, clay, and } \\
\text { ash }\end{array}$ & [14] \\
\hline FC & Decrease & Increase & Sand-kaolin & [15] \\
\hline
\end{tabular}




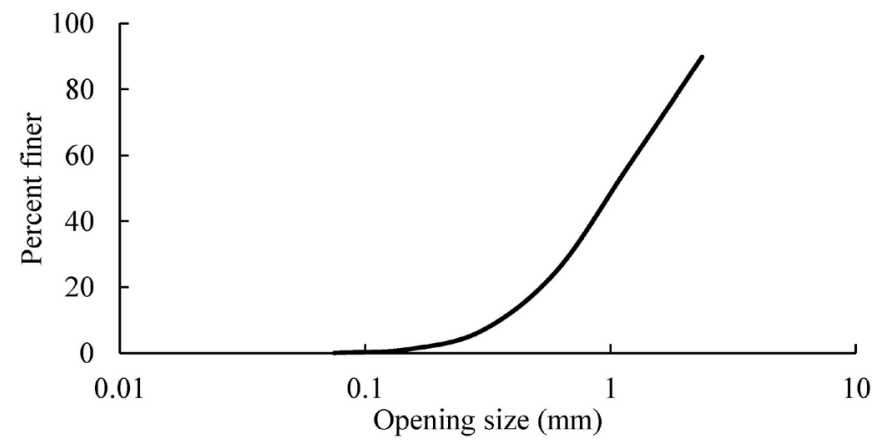

Figure 1. Particle size distribution curve for coarse material (sand)

$\rho_{\text {wet }}=\frac{\left(\mathrm{M}_{\mathrm{t}}-\mathrm{M}_{\mathrm{md}}\right)}{\mathrm{V}}$

$\rho_{d r y}=\frac{\rho_{\text {wet }}}{\left[1+\left(\frac{w}{100}\right)\right]}$

Where $\rho_{\text {wet }}$ is bulk density, $M_{t}$ is the mass of moist soil in mould and mould, $M_{m d}$ is the mass of compaction mould, $V$ is the volume of compaction mould. $\rho_{d r y}$ is the dry density of compaction point and $w$ is the average water content of compaction point.

\section{Results and Discussion}

Table 2 showed the results of equivalent bulk density $\rho_{\text {wet, }}$ maximum dry density and optimum moisture content at different coarse content. The results indicated the highest value of bulk density was $2.16 \mathrm{~g} / \mathrm{cm}^{3}$ at $\mathrm{CC}=80 \%$ and the lowest (i.e. $\rho_{\text {wet }}=1.9 \mathrm{~g} / \mathrm{cm}^{3}$ ) at $\mathrm{CC}=30 \%$. In addition, table 2 showed that the highest specific gravity value $\left(\mathrm{G}_{\mathrm{s}}\right.$ $=2.61$ ) was at $\mathrm{CC}=80 \%$, and the lowest value for the specific gravity $\left(\mathrm{G}_{\mathrm{s}}=2.553\right)$ at $\mathrm{CC}=30 \%$. Figure 2 showed linear relationship between $\mathrm{MDD}$ and CC. It is obvious that the highest value of maximum dry density $\left(\mathrm{MDD}=1.93 \mathrm{~g} / \mathrm{cm}^{3}\right)$ was indicated in $\mathrm{CC}=80 \%$ while the lowest value of maximum dry density $\left(\mathrm{MDD}=1.58 \mathrm{~g} / \mathrm{cm}^{3}\right)$ was in $\mathrm{CC}=30 \%$. The equivalent bulk density $\left(\rho_{\text {wet }}\right)$ corrosponding to the highest MDD was $2.16 \mathrm{~g} / \mathrm{cm}^{3}$. The equivalent bulk density $\left(\rho_{\text {wet }}\right)$ of the lowest MDD was $1.90 \mathrm{~g} / \mathrm{cm}^{3}$. This result was in compliance with the outcomes in Wang et al. [5,6] using clay, silt, sand and gravel, Abu-Farsakh [7] using clay, silt and sand, Dafalla [11] using clay-sand, Santos et al. [12] using ash-soil, Kim et al. [14] using ash-soil, Mir and Sridharan [13] using ash, clay, silt and sand, and Crispim et al. [16] using clay, silt, sand and gravel.

Table 2. The results of bulk density, MDD, and OMC at different coarse content

\begin{tabular}{lllll}
\hline $\mathrm{CC} \%$ & $\mathrm{G}_{\mathrm{s}}$ & $\rho_{\text {wet }}\left(\mathrm{g} / \mathrm{cm}^{3}\right)$ & $\mathrm{MDD}\left(\mathrm{g} / \mathrm{cm}^{3}\right)$ & $\mathrm{OMC}(\%)$ \\
\hline 80 & 2.61 & 2.16 & 1.93 & 12 \\
70 & 2.597 & 2.11 & 1.89 & 12 \\
60 & 2.585 & 2.03 & 1.81 & 12 \\
50 & 2.576 & 1.99 & 1.71 & 16 \\
40 & 2.563 & 1.94 & 1.64 & 18 \\
30 & 2.553 & 1.90 & 1.58 & 20 \\
\hline \multicolumn{5}{c}{ CC: Coarse content, Gs: Specific gravity, OMC: Optimum moisture content, } \\
\multicolumn{5}{r}{ MDD: Maximum dry density, $\rho_{\text {wet }}$ Bulk density }
\end{tabular}

Figure 2 indicated two empirical correlations equations which linked coarse content toward the bulk density and maximum dry density as in the equation 3 and 4 respectively:

\section{$\mathrm{MDD}=0.0073 \mathrm{CC}+1.3566$}

Where $\rho_{\text {wet }}$ is the equivalent bulk density for the maximum dry density, MDD is the maximum dry density, and $\mathrm{CC}$ is the coarse content (i.e. sand content). Equations 3 and 4 has the coefficient of determination $\mathrm{R}^{2}=0.98$. In addition, both equations 3 and 4 were correlated only for sand kaolin mixture with percentage of sand\% between $30 \%$ to $80 \%$.

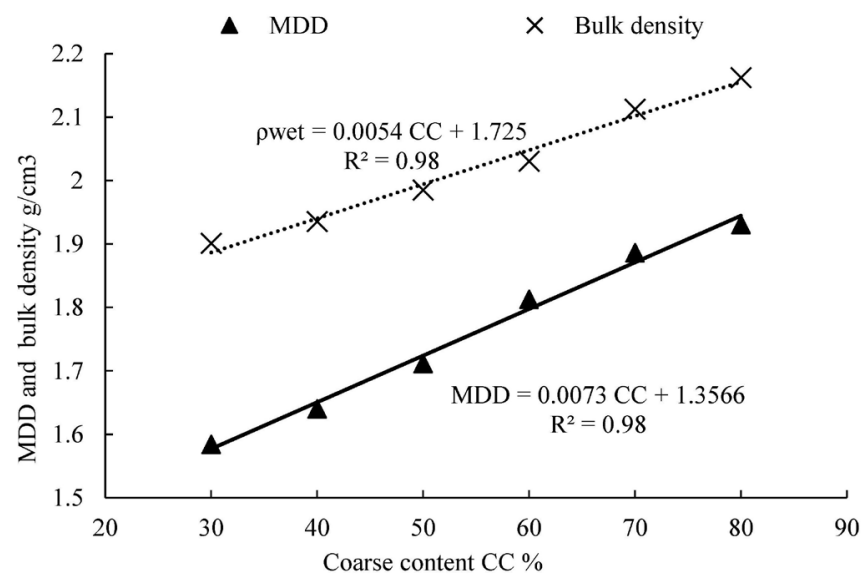

Figure 2. MDD and bulk density versus the coarse content $\mathrm{C}$

Figure 3 showed the results of optimum moisture content versus the coarse content. The results indicated non-liner relationship between the OMC and coarse content. The highest value of OMC was $20 \%$ at coarse content equals to $30 \%$, the lowest one of OMC $=12 \%$ was at three values coarse content from 60,70 and $80 \%$. The similarity in the OMC at CC from 60 to 80 can be related to the interface between the fine content and soil structural. At low fine content (i.e. CC $=80 \%$ ) the moisture content lubricating the contact between the coarse particles and lead to reach the MDD at OMC equal to $12 \%$. However, by increment the fine content, the fine particles will act as lubricating agent side by side with the moisture content which lead to reach MDD at $\mathrm{CC}=80 \%$ using the same moisture content (i.e. OMC $=12 \%$ ). On the other hand, at CC $=50 \%$, the fine particles reduce the effect of the moisture content and produce higher cohesion force which require more moisture content to reposition the coarse particles and reach higher MDD $[17,18]$. The OMC results agreed with outcomes from Wang et al. [5,6], Abu-Farsakh [7] and Omotosho [9]. However, the regressive relationship between OMC and CC can be related to the fine content where the highest fine content, the highest water required to minimizing the effect of the cohesion thus achiving the MDD point [17].

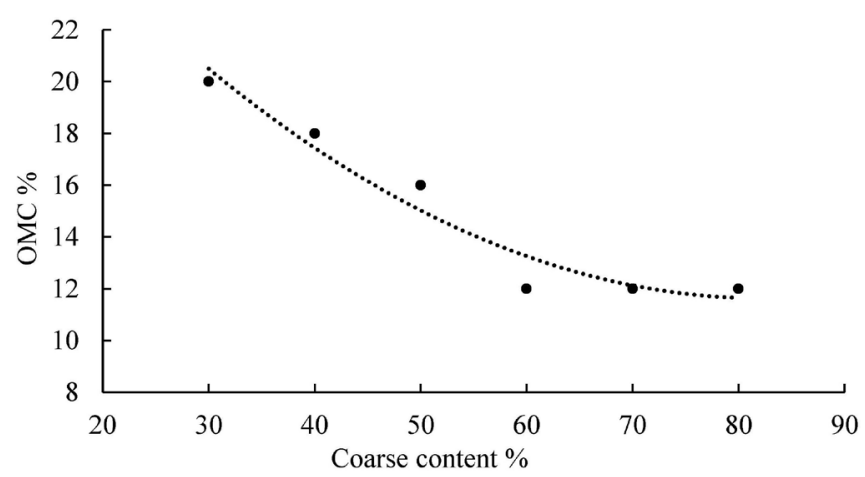

Figure 3. OMC versus the coarse content

The comparison between the current study and previous outcomes from different researchers at Figures 4 and 5 indicated the follows:

- All studies showed the same patterns where the CC has progressive and regressive relationships toward MDD and OMC respectively $[5,9,11,12]$

- At MDD results, the outcomes from Santos et al. (2011) showed close pattern to the current study compare with Wang et al. [5]. This can be related to use crushed sandstone with higher density 
in Wang et al. [5] compare with mixture of soil and ash at Santos et al. [12].

- In the OMC comparison, the outcomes from Omotosho [9] and Dafalla [11] showed close value to the current study where the moisture content was less than 30\% compare with $45.5 \%$ in Santos et al. [12] results. And the material which used in both Omotosho [9] and Dafalla [11] were close the material in current study compare with the ash soil mixture from Santos et al. [12].

On the other hand, the results at figure 6 showed progressive relationship between the specific gravity $\left(G_{s}\right)$ and the coarse content. Figure 7 showed the progressive relationship between the bulk density and maximum dry density with the specific gravity. The increment of MDD with the increasing the coarse content (see figure 2) can be related to the specific gravity where the increasing in coarse content resulted an increment the density (Table 2).

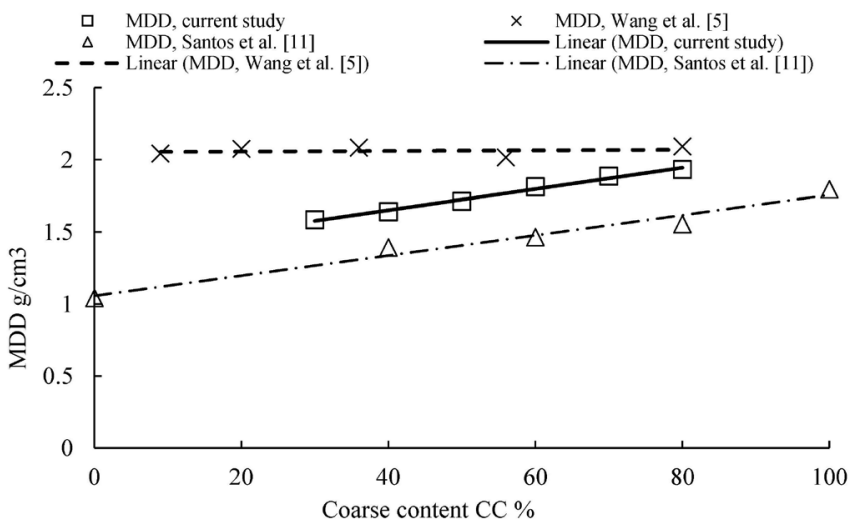

Figure 4. Comparison MDD from current study with previous researchers

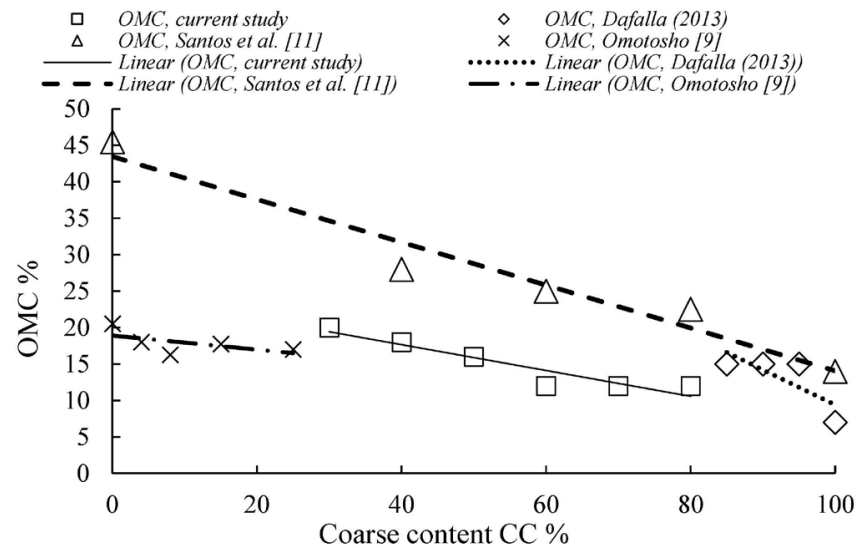

Figure 5. Comparison OMC from current study with previous researchers

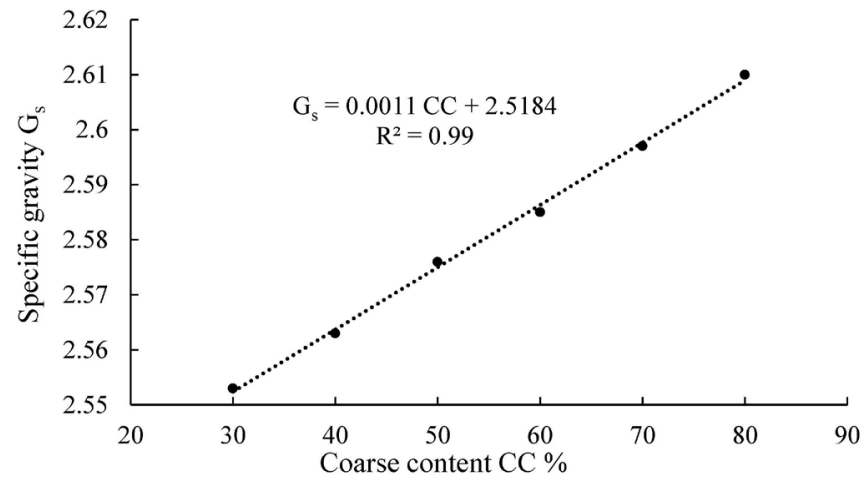

Figure 6. Specific gravity Gs versus the coarse content

By refereeing to Figures 6 and 7, the empirical correlations equations linked the specific gravity toward the coarse content, bulk density, and MDD which list in equations 5, 6 and 7 respectively:

$\mathrm{Gs}=0.0011 \mathrm{CC}+2.5184$

$\rho_{\text {wet }}=4.7573 G_{s}-10.256$

$\mathrm{MDD}=6.4601 \mathrm{Gs}_{\mathrm{s}}-14.91$

Where $\mathrm{G}_{\mathrm{s}}$ is specific gravity, $\mathrm{CC}$ is the coarse content (i.e. sand content), $\rho_{\text {wet }}$ is the equivalent bulk density for the maximum dry density, and MDD is the maximum dry density. The coefficient of determination $\left(R^{2}\right)$ for equation 5,6 , and 7 were $R^{2}=0.99,0.98$ and 0.98 respectively. All of equations 5, 6 and 7 were correlated only for sand-kaolin mixture with percentage of sand\% between $30 \%$ to $80 \%$. The comparison between the Gs, MDD, and CC results from current study and the outcomes from Kulkarni et al. [19] indicated similarity between both results and conform the progressive relationships between $\mathrm{G}_{\mathrm{s}}$, MDD, and $\mathrm{CC}$ (see Figure 8).

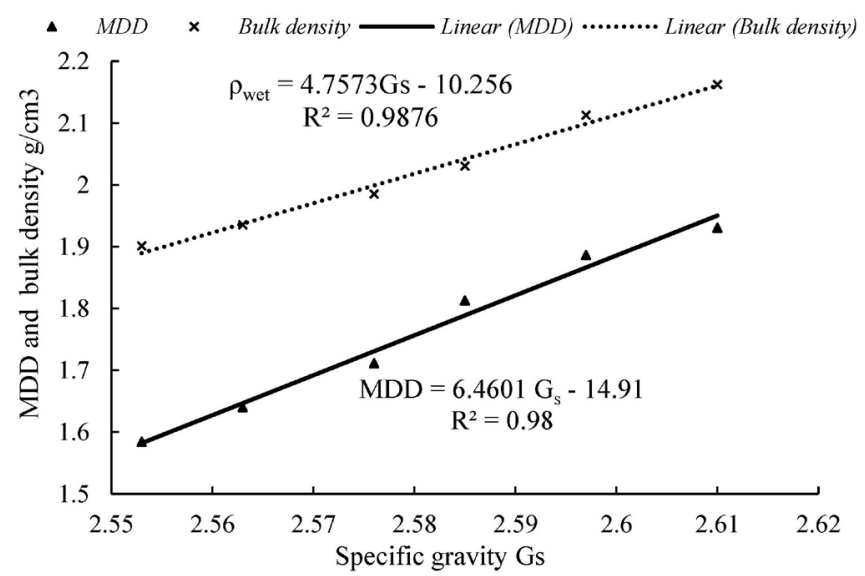

Figure 7. Maximum dry density MDD and bulk density $\rho_{\text {wet }}$ versus the specific gravity Gs 


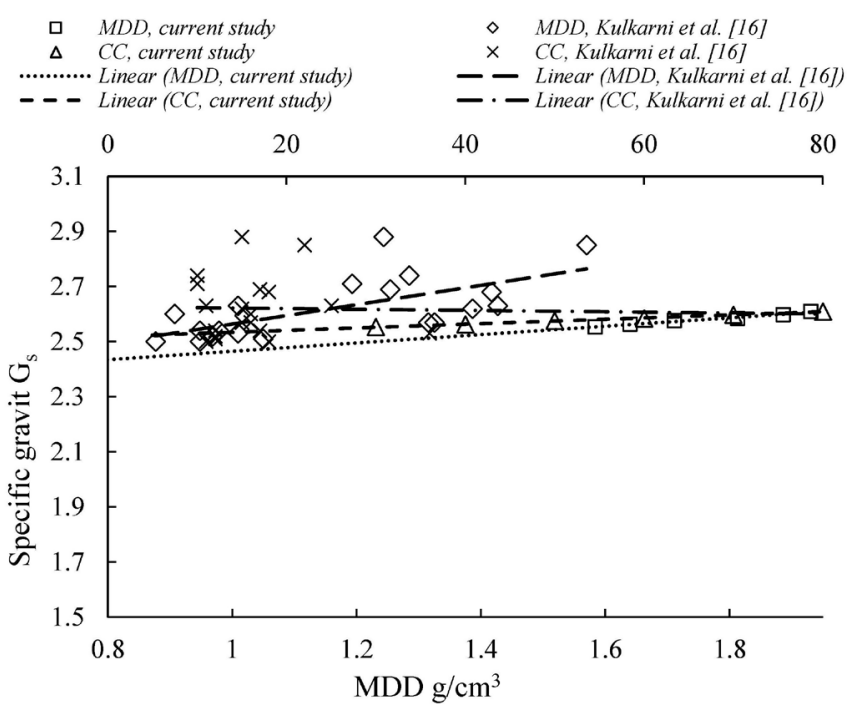

Figure 8. Comparison MDD, Gs, CC from current and previous study

\section{Conclusion}

The effect of coarse content in the maximum dry density MDD, bulk density $\rho_{\text {wet }}$ and OMC was inspected under different mixtures of sandkaolin.

$>\quad$ The study presented five emperical correlation between coarse content, specific gravity, maximum dry density, optimum moisture content and bulk density with coefficient of determination $\left(\mathrm{R}^{2} \geq 0.98\right)$

$>$ The comparison between the current study and previous researchers indicated that both material type and moisture content have significant effect on the efficiency of the empirical correlation equations between the MDD, $\rho_{\text {wet }}$ and $\mathrm{G}_{\text {s }}$ toward coarse content.

$>\quad$ linear relationship between the MDD, $\rho_{\text {wet, }}$, and specific gravity $\mathrm{G}_{s}$ toward the coarse content.

$>\quad$ Non-linear relationship between the OMC and coarse content.

$>$ The higher fine content the more moisture mould content requires to achieve MDD.

\section{Nomenclature}

CC : Coarse content

FC : Fine content

Gs : Specific gravity

OMC : Optimum moisture content

MDD : Maximum dry density

$\rho_{\text {wet }}$ : the equivalent bulk density

\section{Declaration of Conflict of Interests}

The author declares that there is no conflict of interest. They have no known competing financial interests or personal relationships that could have appeared to influence the work reported in this paper.

\section{References}

[1.] ASTM-D698, Standard Test Methods for Laboratory Compaction Characteristics of Soil Using Standard Effort (12400 ft-lbf/ft3 (600 kN-m/m3)), West Conshohocken, PA, 2012. https://doi.org/10.1520/D0698-12E01.1.

[2.] Alshameri, B., Madun, A.,, Bakar, I., Assessment on the effect of fine content and moisture content towards shear strength, Geotech. Eng. 48 (2017) 76-86.
[3.] Comparison of the effect of fine content and density towards the shear strength parameters, Geotech. Eng. (2017). http://www.scopus.com/inward/record.url?eid=2-s2.085019695951\&partnerID=MN8TOARS.

[4.] Alshameri, B., Bakar, I., Madun, A., Abdeldjouad, L.,, Dahlan, S.,H., Effect of Coarse Materials Percentage in the Shear Strength, IOP Conf. Ser. Mater. Sci. Eng. 136 (2016). https://doi.org/10.1088/1757-899X/136/1/012017.

[5.] Wang, J.,J., Zhang, H.,P., Liu, M.,W.,, Deng, D.,P., Compaction behaviour and particle crushing of a crushed sandstone particle mixture, Eur. J. Environ. Civ. Eng. 18 (2014) 567-583. https://doi.org/10.1080/19648189.2014.891469.

[6.] Wang, J.,J., Yang, Y.,, Zhang, H.,P., Effects of Particle Size Distribution on Compaction Behavior and Particle Crushing of a Mudstone Particle Mixture, Geotech. Geol. Eng. 32 (2014) 1159-1164. https://doi.org/10.1007/s10706-014-9782-3.

[7.] Abu-Farsakh, M., Coronel, J.,, Tao, M., Effect of Soil Moisture Content and Dry Density on Cohesive Soil-Geosynthetic Interactions Using Large Direct Shear Tests, J. Mater. Civ. Eng. 19 (2007) 540-549. https://doi.org/10.1061/(ASCE)08991561(2007)19:7(540).

[8.] Alshameri, B., Madun, A., Comprehensive Correlations Between the Geotechnical and Seismic Data Conducted via Bender Element, Geotech. Geol. Eng. 37 (2019). https://doi.org/10.1007/s10706-019-00963-5.

[9.] Omotosho, O., Influence of gravelly exclusion on compaction of lateritic soils, Geotech. Geol. Eng. 22 (2004) 351-359. https://doi.org/10.1023/B:GEGE.0000025036.13997.df.

[10.] Khaleghnejad Tabari, M., TaghaviGhalesari, A., Janalizadeh Choobbasti, A., Afzalirad, M., Large-Scale Experimental Investigation of Strength Properties of Composite Clay, Geotech. Geol. Eng. 37 (2019) 5061-5075. https://doi.org/10.1007/s10706-019-00962-6.

[11.] Dafalla, M.,A., Effects of clay and moisture content on direct shear tests for clay-sand mixtures, Adv. Mater. Sci. Eng. 2013 (2013) 8. https://doi.org/10.1155/2013/562726.

[12.] Santos, F., Li, L., Li, Y., Amini, F., Geotechnical Properties of Fly Ash and Soil Mixtures for Use in Highway Embankments, in: World Coal Ash Conf., Denver, USA, 2011: pp. 125-136.

[13.] Mir, B.,A.,, Sridharan, A., Physical and Compaction Behaviour of Clay Soil-Fly Ash Mixtures, Geotech. Geol. Eng. 31 (2013) 1059-1072. https://doi.org/10.1007/s10706-013-9632-8.

[14.] Kim, B., Prezzi, M.,, Salgado, R., Geotechnical Properties of Fly and Bottom Ash Mixtures for Use in Highway Embankments, J. Geotech. Geoenvironmental Eng. 131 (2005) 914-924. https://doi.org/10.1061/(asce)1090-0241(2005)131:7(914).

[15.] Alshameri, B., Maximum dry density of sand-kaolin mixtures predicted by using fine content and specific

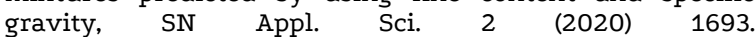
https://doi.org/10.1007/s42452-020-03481-9.

[16.] Crispim, F.,A., de Lima, D.,C., Schaefer, C.,E.,G.,R., Silva, C.,H., de C., de Carvalho, C.,A.,B., Barbosa, P.,S., de A.,, Brandão, E.,H., The influence of laboratory compaction methods on soil structure: Mechanical and micromorphological analyses, Soils and Rocks. 34 (2011) 91-98.

[17.] Mitchell, J.,K.,, Soga, K., Fundamentals of soil behavior, 3rd ed., John Wiley \& Sons, Inc, New Jersey, USA, 2005.

[18.] Alshameri, B., Madun, A.,, Bakar, I., Comparison of the Effect of Fine Content and Density towards the Shear Strength Parameters, Geotech. Eng. 48 (2017) 104-110.

[19.] Kulkarni, M.,P., Patel, A.,, Singh, D.,N., Application of shear wave velocity for characterizing clays from coastal regions, KSCE J. Civ. Eng. 14 (2010) 307-321. https://doi.org/10.1007/s12205-010-0307-1.

\section{How to Cite This Article}

Alshameri, B. Effect of Coarse Content on Compaction Test, Civil Engineering Beyond Limits, 1(2022), 1506.

https://doi.org/10.36937/cebel.2021.1506 